\title{
Papers
}

\section{The cognitive cost of being a twin: evidence from comparisons within families in the Aberdeen children of the 1950s cohort study}

\author{
Georgina A Ronalds, Bianca L De Stavola, David A Leon
}

\begin{abstract}
Objectives To determine whether twins have lower IQ scores in childhood than singletons in the same family and, if so, whether differences in fetal growth explain this deficit.

Design Cohort study.

Setting Scotland.

Participants 9832 singletons and 236 twins born in Aberdeen between 1950 and 1956.

Results At age 7, the mean IQ score of twins was 5.3 points lower (95\% confidence interval 1.5 to 9.1 ) and at age $9,6.0$ points lower (1.7 to 10.2) than that of singletons in the same family. Adjustment for sex, mother's age, and number of older siblings had little effect on these differences. Further adjustment for birth weight and gestational age attenuated the IQ

difference between twins and singletons: the difference in mean IQ was 2.6 points ( -1.5 to 6.7 ) at age 7 and 4.1 points ( -0.5 to 8.8) at age 9 .

Conclusions Twins have substantially lower IQ in childhood than singletons in the same family. This effect cannot be explained by confounding due to socioeconomic, maternal, or other family characteristics, or by recruitment bias. The reduced prenatal growth and shorter gestations of twins may explain an important part of their lower IQ in childhood.
\end{abstract}

\section{Introduction}

For many years, researchers have been asking whether sharing life with a co-twin in the womb or after birth affects cognitive ability. ${ }^{1}$ The question is not only of importance to researchers who are interested in twins but may help to explain the determinants of cognitive ability more generally. Childhood cognition is predictive of educational attainment, socioeconomic position, and health in adulthood and therefore has important social and public health implications. ${ }^{2-4}$

Most previous studies reported that twins have lower cognitive ability than singletons. In a very large study of children born in Birmingham, United Kingdom, between 1950 and 1954, twins had a deficit in verbal reasoning scores at age 11 of 4.4 points on average. ${ }^{5}$ In the US collaborative perinatal project of hospital births delivered in 1959-65, twins scored lower in cognitive tests at 8 months, 4 years, and 7 years, although substantial loss to follow up had occurred by 7 years. ${ }^{6}$ In a national sample of Australian schoolchildren born in the 1960s, singletons performed better than twins in tests of word knowledge, reading, and numeracy at ages 10 and $14 .^{7}$ Similarly, among 10 year olds in Stockholm born in 1953, singletons tended to have higher verbal ability and numerical test scores than twins. ${ }^{8}$ Most recently, a study was reported that used the Netherlands twin registry to look at differences within families in cognition between 260 adult twins and 98 of their singleton siblings. This found no evidence for a difference in cognitive ability between singletons and twins in the same family. ${ }^{9}$

Despite these various studies it is still unclear whether something intrinsic to the experience in the womb of being a twin is associated with a cognitive deficit. Maternal characteristics and other aspects of the postnatal family and socioeconomic environment are clearly different between twins and singletons ${ }^{10}$; many of these aspects are known to be related to cognitive ability. ${ }^{11-15}$ Much of this potential confounding by familial factors can be dealt with by studying whether twins have a cognitive deficit compared with their singleton brothers or sisters in the same family. However, the only study to date to take this approach did not adjust for factors that vary between siblings in the same family, such as maternal age and order among siblings. ${ }^{9}$

We used a within family design to investigate the deficit in cognition between twins and singletons. However, instead of using a twin registry we identified families containing twins and singletons from a representative cohort of all people born in Aberdeen, Scotland, and attending primary school there in 1962. We also take our analysis further than others by looking at how far any true twin deficit results from reduced intrauterine growth of twins or shorter gestation.

\section{Methods}

\section{Subjects and data}

Our study subjects participated in the Aberdeen children of the 1950s study. ${ }^{16}$ This is comprised of 12150 individuals born in Aberdeen between 1950 and 1956 and who took part in the Aberdeen child development survey (1962-64) of all children in Aberdeen primary schools in December $1962 .{ }^{17}$ A large number of participants (5048) have a sibling in the cohort. Siblings were identified by the original Aberdeen child development survey team, using information provided by schools in 1962 .

During the primary school careers of our subjects, all children at Scottish primary schools were routinely given written cognitive tests at around the ages of 7 and 9 . The original survey team in 1962 abstracted information about the test scores from school records. Tests were administered within six months of the child's 7th or 9th birthday. Age standardised IQ scores were derived from the test results and were normalised to a national mean of 100 (SD 15). Of the study participants, 11669 took the test at age 7 and 11376 at age 9. The Moray House picture intelligence test No 1 or 2 was used at age 7 . This is a test based on recognition and understanding of differences between sets of line drawn pictures. At age 9, children took the Schonell and 
Adams essential intelligence test form A or B, which primarily measured reading ability.

Data on singleton or multiplet status, mother's age at delivery (in five year age bands), birth weight (to the nearest $0.5 \mathrm{lb}$ ), gestational age (in completed weeks based on date of last menstrual period), and father's occupational social class at the time of delivery were abstracted from the Aberdeen maternity and neonatal databank $^{18}$ at the time of the original survey in 1962 . We have taken each child's birth weight for gestational age $\mathrm{z}$ score as a measure of their intrauterine growth rate. We used sex specific mean and standard deviations of birth weight for each completed week of gestation among all births in the study for our calculation. We obtained information on the number of older siblings (excluding any co-twin) from a questionnaire administered in 1962 by the original study team. We do not consider information on order of delivery of each twin to be reliable in these data. As a result for the purposes of this analysis we assigned both members of a twin pair to the birth order of the firstborn twin.

\section{Statistical methods}

We compared the mean IQ values measured at ages 7 and 9 years of singletons and twins overall and across categories of the available potential confounders. We used analysis of variance to assess the significance of differences between groups and linear trends in mean IQ values. ${ }^{19}$

To account for sibling correlations we used random effects linear regression models to calculate crude overall mean differences in IQ between twins and singletons. ${ }^{20}$ We used fixed effects linear regression to estimate differences within families in mean IQ of twins and singletons..$^{20}$ These differ from those obtained from the random effects models because they control directly for fixed family characteristics. We adjusted for observed potential confounders by introducing them into the models, at first separately and then jointly.

We modelled IQ as a continuous dependent variable. Birth weight, gestational age, and birth weight $\mathrm{z}$ score seemed to have non-linear associations with IQ. We therefore included these variables as either categorical variables (gestational age 33-37 weeks, 38-39 weeks, 40-41 weeks, and $\geq 42$ weeks; birth weight $<5.5 \mathrm{lb}(<2495 \mathrm{~g}), 5.5-6.0 \mathrm{lb}(2495-2947 \mathrm{~g}), 6.5 \mathrm{lb}$ (2948-3174 g), 7.0-7.5 lb (3175-3628 g), $\geq 8.0 \mathrm{lb}$ ( $\geq 3629 \mathrm{~g}$ ); birth weight $\mathrm{z}$ score fourths $\leq 0.61,-0.61,-0.04,-0.05,0.63, \geq 0.64)$ or as continuous variables transformed according to the best fitting fractional polynomial function, best to represent the relation between IQ and the continuous explanatory variables, including repeated powers. ${ }^{21}$ With this latter approach the regression model might include more than one transformation of the variables. For example, with two such transformations for birth weight-say, one linear and the other square root-there would be two corresponding powers: a power of 1 for the linear and a power of $1 / 2$ for the square root transformation.

In the results we present effects adjusted for the continuous versions of birth weight, gestational age, and birth weight $\mathrm{z}$ score, because without exception these seem to be stronger confounders of the difference between twins and singletons in IQ than their categorical equivalents. We categorised the remaining variables as number of older siblings $(0,1,2, \geq 3)$; maternal age at delivery (15-24 years, 25 -29 years, $30-34$ years, $\geq 35$ years); registrar general's occupational social class of father at child's birth (I, II, III, IV, V); and a category for unemployed, disabled, or deceased.

\section{Results}

According to maternity hospital records, of the 12150 members of the children of the 1950 s cohort, 10 were triplets, 306 were twins, and 11834 were singletons. Excluding the triplets, data on maternal age, father's social class, birth weight, and number of older siblings were available for more than 12000 (about 99\%) of the study sample (respectively 12 134, 12 139, 12118 and $12050)$. Gestational age was available for $10883(90 \%)$, while IQ at 7 and 9 was available for $11669(93 \%)$ of the subjects. To obtain comparable estimates we excluded 910 participants because they were missing one or both IQ scores. Of the remaining 11230 twins and singletons, 1132 had missing data on gestational age and we also excluded these, together with a further 30 who had missing data on other covariates. This left 10068 participants with complete data, whom we included in multivariable regression analyses (9832 singletons and 236 twins, who together belonged to 8160 families).

Participants excluded from our study had a significantly $(\mathrm{P}<0.001)$ lower mean score at age 7 than those included. The IQ difference was 7.4 points ( $95 \%$ confidence interval 6.6 to 8.3 ). They also had a significantly $(\mathrm{P}<0.001)$ lower mean score at age 9 (IQ difference 5.5 points, 4.6 to 6.5 )). This was partly explained by the fact that those with very low IQs at age 7 or 9 may have been less likely to be tested at either or both ages, as a proportion would have been in special schools where the standard test was not routinely given. In addition, subjects with missing gestational age included a disproportionate number with low birth weight, which is associated with impaired later cognition. ${ }^{22} 23$

As expected, twins tended to be born smaller and earlier in gestation than singletons and also to be born smaller for their gestational age (table 1). Twins had a greater number of older siblings than singletons on average, indicating that mothers with higher parity (and hence older age) were more likely to deliver twins. The difference in the distribution of father's social class between twins and singletons did not reach significance $(\mathrm{P}=0.35)$.

We found that singletons had significantly higher mean IQ scores than twins $(\mathrm{P}<0.001$ at both ages). The crude overall difference was 6.6 points at age 7 (4.4 to 8.8 ) and 6.9 points at age 9 (4.5 to 9.2). IQ at both ages showed positive linear trends, and for both singletons and twins, across categories of birth weight and gestational age while we found a graded inverse trend with number of older siblings and paternal social class (although this was weaker among twins, table 1).

As shown in table 2, sex, maternal age, number of older siblings, and father's social class at birth explain little of the mean IQ difference between twins and singleton at either age. However, adjustment for birth weight, gestational age, or birth weight $\mathrm{z}$ score reduces these differences substantially. The results, however, are still potentially confounded by unmeasured shared maternal and family characteristics that can be controlled for when computing effects within families. Table 3 shows unadjusted differences within families in mean IQ between twins and singletons that are only slightly smaller than the equivalent ones of table 2. As was the case there, sex, maternal age, and number of older siblings have very few confounding effects (paternal social class was effectively fixed in families and therefore not adjusted for). The difference in mean IQ between singletons and twins was again reduced substantially when controlled for birth weight. This adjusted estimate was similar to that produced by simultaneous adjustment for birth weight and gestational age. 
Table 1 Frequency distribution and mean (SD) IQ at age 7 and 9, by categories of birth and childhood characteristics, separately for singletons and twins. Values are numbers (percentages) of children unless otherwise indicated

\begin{tabular}{|c|c|c|c|c|c|c|}
\hline \multirow[b]{3}{*}{ Variable } & \multicolumn{3}{|c|}{ Singletons } & \multicolumn{3}{|c|}{ Twins } \\
\hline & \multirow[b]{2}{*}{ No (\%) } & \multicolumn{2}{|c|}{ Mean IQ (SD) } & \multirow[b]{2}{*}{ No $(\%)$} & \multicolumn{2}{|c|}{ Mean IQ (SD) } \\
\hline & & Age 7 & Age 9 & & Age 7 & Age 9 \\
\hline Overall & $9832(100.0)$ & $108.2(15.7)$ & $112.1(16.8)$ & $236(100.0)$ & $101.3(15.8)$ & $105.1(17.6)$ \\
\hline \multicolumn{7}{|l|}{ Sex: } \\
\hline Female & $4695(47.8)$ & $108.6(15.8)$ & $112.8(16.0)$ & $106(44.9)$ & 99.8 (15.5) & 104.3 \\
\hline $\begin{array}{l}\text { Male } \\
\end{array}$ & $5137(52.2)$ & $107.9(15.6)$ & 111.5 (17.5) & $130(55.1)$ & $102.6(16.0)$ & $105.8(19.2)$ \\
\hline Heterogeneity $\dagger$ & & 0.03 & $<0.001$ & & 0.18 & 0.52 \\
\hline \multicolumn{7}{|l|}{ Birth weight in $\mathrm{lb}$ : } \\
\hline $\begin{array}{l}<5.5 \\
\end{array}$ & $410(4.2)$ & $103.3(15.4)$ & $107.5(17.3)$ & $111(47.0)$ & $97.3(14.5)$ & $100.9(15.8)$ \\
\hline 5.5 to 6.0 & 1620 (16.5) & $106.3(15.5)$ & $110.8(16.2)$ & $69(29.2)$ & $103.5(15.8)$ & $107.9(18.7)$ \\
\hline 6.5 & $1589(16.2)$ & $107.7(15.8)$ & $111.3(16.8)$ & $24(10.2)$ & $107.5(15.6)$ & $109.0(16.6)$ \\
\hline 7.0 to 7.5 & $3627(36.9)$ & $108.6(15.7)$ & $112.6(17.1)$ & $30(12.7)$ & $106.1(18.0)$ & $110.1(19.7)$ \\
\hline$\geq 8.0$ & $2586(26.3)$ & $110.1(15.4)$ & $113.4(16.6)$ & $2(0.9)$ & $106.0(5.7)$ & $118.0(18.4)$ \\
\hline Linear trend† & & $<0.001$ & $<0.001$ & & $<0.001$ & $<0.001$ \\
\hline \multicolumn{7}{|l|}{ Gestational age in weeks: } \\
\hline 33 to 37 & $599(6.1)$ & $104.7(15.6)$ & $108.5(17.5)$ & $89(37.7)$ & $96.6(15.4)$ & $100.1(15.7)$ \\
\hline 38 to 39 & 1929 (19.6) & $107.6(15.5)$ & $112.0(16.6)$ & $82(34.8)$ & $104.0(14.2)$ & $108.5(17.1)$ \\
\hline 40 to 41 & $5179(52.7)$ & 109.1 (15.6) & $112.8(16.7)$ & $56(23.7)$ & $102.8(16.5)$ & $106.5(20.1)$ \\
\hline $42+$ & $2125(21.6)$ & $107.8(16.0)$ & $111.5(17.0)$ & $9(3.8)$ & $115.1(16.7)$ & $115.3(11.6)$ \\
\hline Linear trend $\dagger$ & & $<0.001$ & $<0.001$ & & $<0.001$ & $<0.001$ \\
\hline \multicolumn{7}{|c|}{ Birth weight for gestational age (z score): } \\
\hline$\leq 0.61$ & $2380(24.2)$ & $106.0(15.6)$ & $110.0(16.5)$ & $144(61.0)$ & $102.0(15.5)$ & $104.8(17.7)$ \\
\hline-0.61 to -0.04 & $2470(25.1)$ & $108.1(15.9)$ & $111.8(16.9)$ & $53(22.5)$ & $101.5(16.6)$ & $108.1(16.1)$ \\
\hline-0.05 to 0.63 & $2518(25.6)$ & $108.9(15.6)$ & $113.1(17.1)$ & $32(13.6)$ & $100.1(15.9)$ & $102.6(19.6)$ \\
\hline$\geq 0.64$ & $2464(25.0)$ & $109.9(15.4)$ & $113.4(16.6)$ & $7(3.0)$ & $91.9(16.8)$ & $99.1(17.1)$ \\
\hline Linear trend $†$ & & $<0.001$ & $<0.001$ & & 0.18 & 0.57 \\
\hline \multicolumn{7}{|c|}{ Maternal age at delivery, in years: } \\
\hline $15-24$ & 3496 (35.6) & $106.1(15.1)$ & $110.5(16.1)$ & $51(21.6)$ & $101.5(15.2)$ & $102.9(17.0)$ \\
\hline $25-29$ & $3111(31.6)$ & $109.2(15.8)$ & $112.6(17.1)$ & $78(33.1)$ & $101.1(14.5)$ & $106.5(16.5)$ \\
\hline $30-34$ & $2089(21.3)$ & 109.8 (15.9) & $113.5(17.1)$ & $72(30.5)$ & $100.4(16.9)$ & $105.1(19.4)$ \\
\hline$\geq 35$ & 1136 (11.6) & $109.7(15.7)$ & $113.1(17.4)$ & $35(14.8)$ & $103.7(17.6)$ & $105.3(17.4)$ \\
\hline Linear trend $\dagger$ & & $<0.001$ & $<0.001$ & & 0.80 & 0.51 \\
\hline \multicolumn{7}{|l|}{ No of older siblingsł: } \\
\hline 0 & $3826(38.9)$ & $109.3(15.6)$ & $115.1(16.2)$ & $47(19.9)$ & $103.3(15.4)$ & $109.9(15.1)$ \\
\hline 1 & $3090(31.4)$ & $109.7(15.6)$ & $113.1(16.8)$ & $101(42.8)$ & $101.8(14.0)$ & $107.0(16.7)$ \\
\hline 2 & $1600(16.3)$ & $105.8(15.1)$ & $108.9(16.6)$ & $40(17.0)$ & $99.9(18.8)$ & $99.4(21.0)$ \\
\hline$\geq 3$ & $1316(13.4)$ & $102.3(14.9)$ & $104.8(16.1)$ & $48(20.3)$ & 99.8 (17.5) & $102.0(16.9)$ \\
\hline Linear trend $†$ & & $<0.001$ & $<0.001$ & & 0.23 & $<0.01$ \\
\hline \multicolumn{7}{|c|}{ Father's social class at birth: } \\
\hline 1 & $196(2.0)$ & $123.1(12.4)$ & $126.9(15.5)$ & $8(3.4)$ & $112.0(20.4)$ & $116.5(24.5)$ \\
\hline II & $693(7.1)$ & $118.7(14.6)$ & $122.8(16.4)$ & $10(4.2)$ & $116.8(18.0)$ & $107.6(17.6)$ \\
\hline III & $5620(57.2)$ & $109.6(15.3)$ & $113.5(16.3)$ & $134(56.8)$ & $101.8(15.3)$ & $105.4(16.9)$ \\
\hline IV & $1388(14.1)$ & $103.7(14.1)$ & $107.8(15.3)$ & $33(14.0)$ & $103.9(16.6)$ & $108.2(14.7)$ \\
\hline V & $1531(15.6)$ & $101.9(14.3)$ & $105.4(15.8)$ & $41(17.4)$ & $92.9(14.0)$ & $95.8(18.5)$ \\
\hline Dead or unemployed & $404(94.1)$ & $103.6(15.4)$ & $107.7(17.2)$ & $10(4.2)$ & $107.3(8.0)$ & $118.1(10.1)$ \\
\hline Linear trend $\dagger$ & & $<0.001$ & $<0.001$ & & 0.09 & 0.53 \\
\hline
\end{tabular}

TP value for the test for heterogeneity or linear trend in mean $I Q$ values across the categories of each variable (excluding missing).

\section{Discussion}

Consistent with other studies we found strong evidence of an appreciable cognitive deficit, of more than 6 IQ points, in twins compared with singletons at ages 7 and 9, among children who attended primary school in Aberdeen in 1962. Most importantly, we have also shown that differences in IQ between twins and singletons of the same order are found within families. These differences persisted after adjustment for maternal age and number of older siblings. We also replicated associations between cognition, socioeconomic position, and size at birth, and differences between twins and singletons in maternal age and birth order that have been well established in the literature, ${ }^{10-14}$ which led us to conclude that our data have a basic validity.

\section{Limitations of the study}

This study has several limitations. The cognitive tests were given in a routine school context supervised by class teachers. It could therefore be argued that even stronger effects may have been observed if instead tests had been administered by using a more standardised, research protocol. We excluded almost 20\% of subjects because of missing data. However, it is difficult to imagine how this may have biased our key findings, particularly with respect to differences between twins and singletons within families. Finally, we had limited information on potential confounders. As discussed below, however, many of the potentially important confounders that are missing in studies of children's IQ, such as parental IQ, cannot have any role in explaining the effects within families that we observed. 
Table 2 Estimates of crude and adjusted overall mean differences in IQ between singletons and twins, at ages 7 and 9

Mean difference in IQ in singletons $v$ twins $(95 \%$

\begin{tabular}{lcc}
\cline { 2 - 3 } Adjusted for: & At age 7 & At age 9 \\
\hline None & $6.6(4.4$ to 8.8$)$ & $6.9(4.5$ to 9.2$)$ \\
\hline Sex & $6.6(4.4$ to 8.8$)$ & $6.9(4.5$ to 9.2$)$ \\
\hline Maternal age at delivery & $7.0(4.8$ to 9.2$)$ & $7.2(4.8$ to 9.6$)$ \\
\hline Number of older siblings & $6.5(4.3$ to 8.6$)$ & $6.3(4.0$ to 8.7$)$ \\
\hline Father's social class at birth & $6.4(4.3$ to 8.5$)$ & $6.7(4.4$ to 8.9$)$ \\
\hline Birth weight (continuous*) & $3.1(0.8$ to 5.4$)$ & $3.8(1.3$ to 6.3$)$ \\
\hline Gestational age (continuous†) & $4.7(2.5$ to 6.9$)$ & $5.1(2.7$ to 7.5$)$ \\
\hline Birth weight z score (continuous $\ddagger)$ & $4.9(2.7$ to 7.1$)$ & $5.3(2.9$ to 7.7$)$ \\
\hline
\end{tabular}

See statistical methods for details of transformation notation.

* Birth weight was modelled by using a transformation to the $(-2,-2)$ power, where the second transformation differs from the first by multiplication by log (birth weight), for the analysis of $I Q$ at age 7 and $(1,2)$ power for the analysis of $I Q$ at age 9 .

†Gestational age was modelled by using a transformation to the $(3,3)$ power, where the second transformation differs from the first by multiplication by log (gestational age), for the analysis of $I Q$ at age 7 and at age 9 .

$\ddagger$ Birth weight $z$ score was modelled by using a transformation to the $(0.5,3)$ power for the analysis of $I Q$ at age 7 and $(1,3)$ power for the analysis of $I Q$ at age 9 .

Our within family analysis provided a particularly powerful way of removing the potential confounding effects of those aspects of the family environment that are shared by twins and singletons in the same family, such as parental IQ and educational level. The fact that the size of the differences between twins and singletons in the overall analysis was very similar to that found in the within family analysis, and that paternal social class, maternal age, and number of older siblings seem to show very little confounding effect, means that these differences cannot be explained by the characteristics of families who have twins and those who do not. Nevertheless it is still quite possible that aspects of non-shared postnatal environment between twins and singletons may have an important role in explaining the observed IQ differences within families. However, we have almost no information about such factors.

\section{Comparison with other studies}

Our results from the within family analysis are in disagreement with the only sizeable study that compared twins and singletons in the same family. ${ }^{9}$ This discrepancy may well be explained by

Table 3 Mean differences (95 confidence intervals) in $1 Q$ within families between singletons and twins, at ages 7 and 9

\begin{tabular}{|c|c|c|}
\hline $\begin{array}{l}\text { Adjustment for confounders within } \\
\text { families }\end{array}$ & At age 7 & At age 9 \\
\hline None & 5.3 (1.5 to 9.1$)$ & 6.0 (1.7 to 10.2$)$ \\
\hline Sex & 5.3 (1.6 to 9.1$)$ & 6.0 (1.7 to 10.2$)$ \\
\hline Maternal age at delivery & 5.5 (1.8 to 9.3$)$ & $6.2(1.9$ to 10.5$)$ \\
\hline No of older siblings & 5.1 (1.3 to 8.9) & 5.3 (1.0 to 9.6$)$ \\
\hline Birth weight (continuous*) & $2.8(-1.3$ to 6.9$)$ & $4.3(-0.3$ to 8.9$)$ \\
\hline Gestational age (continuous $†$ ) & 4.7 (0.8 to 8.6) & 5.7 (1.3 to 10.1) \\
\hline Birth weight z score (continuous $\ddagger$ ) & 4.0 (0.1 to 7.9$)$ & 5.0 (0.6 to 9.4$)$ \\
\hline $\begin{array}{l}\text { Sex, maternal age at delivery and number } \\
\text { of older siblings }\end{array}$ & 5.4 (1.6 to 9.3$)$ & $5.7(1.4$ to 10.0$)$ \\
\hline $\begin{array}{l}\text { Birth weight and gestational age } \\
\text { (continuous }{ }^{\star} \dagger \text { ) }\end{array}$ & $2.6(-1.5$ to 6.7$)$ & $4.1(-0.5$ to 8.8$)$ \\
\hline $\begin{array}{l}\text { Birth weight z score and gestational age } \\
\text { (continuous* }{ }^{\star} \dagger \text { ) }\end{array}$ & $2.9(-1.2$ to 7.0$)$ & $4.3(-0.3$ to 8.9$)$ \\
\hline
\end{tabular}

See statistical methods for details of transformation notation.

*Birth weight was modelled by using a transformation to the $(-2,-2)$ power, where the second transformation differs from the first by multiplication by log (birth weight), for the analysis of $I Q$ at age 7 and $(1,2)$ power for the analysis of $I Q$ at age 9 .

tGestational age was modelled by using a transformation to the $(3,3)$ power, where the second transformation differs from the first by multiplication by log (gestational age), for the analysis of $I Q$ at age 7 and at age 9 .

łBirth weight $z$ score was modelled by using a transformation to the $(0.5,3)$ power for the analysis of IQ at age 7 and $(1,3)$ power for the analysis of IQ at age 9 . recruitment bias. Posthuma et al drew their sample from adults in the Netherlands twin registry. ${ }^{24}$ The index twins who agreed to take part in that study are unlikely to have been representative of the total population of twins. In particular, those with lower IQs are likely to have been under-represented. However, the singletons who were recruited by their twin siblings would not have been subject to such a strong bias. This would have led Posthuma et al to underestimate the twin deficit in cognition relative to our study. Our study, which is based on a whole population cohort, does not have this problem.

We took our analyses further than others by exploring whether the adverse effect of twinship on cognitive development can be attributed to the impaired growth of twins in the womb and their shorter average gestations. We found strong evidence that the lower birth weight of twins explained an important fraction of the differences between twins and singletons, and adjustment for this on its own or with the addition of gestational age practically halved the effect at age 7 and reduced it by almost $30 \%$ at age 9 . Our data on gestational age were based on date of last menstrual period and included some that were classified in the obstetric notes as being "uncertain." Moreover, birth weight was recorded only to the nearest half pound (225 g). It is possible that if we had more precise data on these factors, adjustment for them would have produced an even larger attenuation of effect.

These findings are consistent with the positive association between birth weight and IQ that has been shown in several studies. ${ }^{13}{ }^{25-27}$ Sharing the intrauterine environment, including the nutrient supply, with a co-twin may impair cognitive, as well as somatic, development. On the other hand, cognitive disadvantage may be incurred later in development and be associated with size at birth because of tracking of growth through childhood. Alternatively, effects of the intrauterine environment may be part of a chain of developmental events leading to the accumulated deficit in IQ in twins by age 7.

\section{Conclusions}

Cognitive ability is strongly associated with educational attainment, adult socioeconomic position, and mental and physical health..$^{-4}$ A cognitive deficit in twins of this magnitude is therefore clearly of long term importance. However, our observations are based on a cohort born more than 50 years ago. Moreover, the other published literature on this is based on populations delivered at least 35 years ago. ${ }^{5-9}$ Nevertheless it is clear, despite progress in obstetric practice and neonatal care, that even among recent birth cohorts these perinatal characteristics are predictive of various developmental and cognitive deficits. To this extent, it seems very likely that there will still be differences in cognition between twins and singletons because of the shorter gestations and impaired fetal growth that affect some twins. However, whether the effects today are as large as we have reported requires study of a more contemporary cohort.

We thank Raymond Illsley for providing us with the data from the Aberdeen Child Development Survey and for his advice about the study.

Contributors: GAR conducted the statistical analysis and drafted the paper. BLDS advised on and supervised the within family analysis and supervised statistical reporting. DAL developed the aim of this study, coordinated revitalisation of the cohort and contributed to writing the paper. All authors contributed to interpretation of the data and to the text of the final draft. DAL is the guarantor for this paper. Contributions of others: Heather Clark manages the Aberdeen children of the 1950s datasets. Graeme Ford had a crucial role in identifying individual cohort members and in helping us initiate the process of revitalisation. G David Batty, Doris Campbell, George Davey Smith, BLDS, Marion Hall, David Godden, Diana Kuh, Glyn Lewis, Sally Macintyre, Susan M B Morton, and Viveca Östberg collaborated with the authors to revitalise the cohort. Margaret Beveridge assisted in the study management. We would also like to thank staff at the Information Services 


\section{What is already known on this topic}

Intelligence in childhood is predictive of educational attainment, socioeconomic position, and health in adulthood

Twins have a lower IQ in childhood than singletons, which has not been not adequately accounted for confounding by maternal characteristics or family and socioeconomic environment

No previous studies have investigated how far this difference in IQ between twins and singletons is due to fetal growth

\section{What this study adds}

On average, twins have lower IQ scores at ages 7 and 9 than singleton children in the same family

The lower intelligence of twins in childhood may partly be a consequence of the reduced fetal growth and shorter gestations of twins

Division (Edinburgh), the General Register Office for Scotland, and the National Health Service Central Register (Southport) for their substantial contributions and John Lemon who undertook the linkage to the Aberdeen maternity and neonatal databank.

Funding: The Aberdeen children of the 1950s study was funded as a component project (G0828205) of a Medical Research Council Co-operative Group on Life-course and trans-generational influences on disease risk (G9819083) GAR was funded by grant from the Scottish Chief Scientist Office.

Competing interests: None declared.

Ethics approval: The Scottish multicentre research ethics committee and local research ethics committees and the Scottish privacy advisory committee approved the revitalisation of the children of the 1950s cohort. All record linkage was undertaken by Information Services Division (Edinburgh), which provided us with an anonymised dataset for analysis.

1 Mehotra SN, Maxwell J. The intelligence of twins. A comparative study of eleven-yearold twins. Population Studies 1949;3:295-302.

2 Batty GD, Deary IJ. Early life intelligence and adult health. BMJ 2004;329:585-6.

3 Deary IJ, Whiteman MC, Starr JM, Whalley LJ, Fox HC. The impact of childhood intelligence on later life: following up the Scottish mental surveys of 1932 and 1947.J Pers Soc Psychol 2004;86:130-47.

4 Hart CL, Taylor MD, Davey SG, Whalley LJ, Starr JM, Hole DJ, et al. Childhood IQ social class, deprivation, and their relationships with mortality and morbidity risk in later life: prospective observational study linking the Scottish Mental Survey 1932 and the Midspan studies. Psychosom Med 2003;65:877-83.

5 Record RG, McKeown T, Edwards JH. An investigation of the difference in measured intelligence between twins and single births. Ann Hum Genet 1970;34:11-20.
6 Myrianthopoulos NC, Nichols PL, Broman SH. Intellectual development of twins-comparison with singletons. Acta Genet Med Gemellol (Roma) 1976;25:376-80.

7 Hay DA, O'Brien PJ, Johnston CJ, Prior M. The high incidence of reading disability in twin boys and its implications for genetic analyses. Acta Genet Med Gemellol (Roma) 1984;33:223-36.

8 Alin AB, Fischbein S. Twins: are they at risk? A longitudinal study of twins and nontwins from birth to 18 years of age. Acta Genet Med Gemellol (Roma) 1991;40:29-40.

9 Posthuma D, de Geus EJ, Bleichrodt N, Boomsma DI. Twin-singleton differences in intelligence? Twin Res 2000;3:83-7.

10 Bulmer MG. The biology of twinning in man. Oxford: Clarendon Press, 1970.

11 Record RG, McKeown T, Edwards JH. The relation of measured intelligence to birth order and maternal age. Ann Hum Genet 1969;33:61-9.

12 Najman JM, Aird R, Bor W, O'Callaghan M, Williams GM, Shuttlewood GJ. The generational transmission of socioeconomic inequalities in child cognitive development and emotional health. Soc Sci Med 2004;58:1147-58.

13 Osler M, Andersen AM, Due P, Lund R, Damsgaard MT, Holstein BE. Socioeconomic position in early life, birth weight, childhood cognitive function, and adult mortality. A longitudinal study of Danish men born in 1953. J Epidemiol Community Health 2003;57:681-6.

14 Shenkin SD, Starr JM, Pattie A, Rush MA, Whalley LJ, Deary IJ. Birth weight and cognitive function at age 11 years: the Scottish mental survey 1932. Arch Dis Child tive finction at a

15 Lawlor DA, Batty GD, Morton SM, Deary IJ, Macintyre S, Ronalds G, et al. Early life predictors of childhood intelligence: evidence from the Aberdeen children of the 1950s study. J Epidemiol Community Health 2005;59:656-63.

16 Batty GD, Morton SMB, Campbell D, Clark H, Davey-Smith G, Hall M, et al. The Aberdeen children of the 1950 s cohort study: background, methods and follow-up information on a new resource for the study of life-course and intergenerational effects on health. Paed Perinat Epidemiol 2004;18:221-39.

17 Birch HG, Richardson SA, Baird D, Horobin G, Illsley R. Mental subnormality in the community: a clinical and epidemiologic study. Baltimore: Williams and Wilkins, 1970.

18 Samphier ML, Thompson B. Longitudinal studies in Aberdeen, Scotland. B. The Aberdeen maternity and neonatal databank. In: Mednick S, Baert A, Bachmann B, eds. Prospective longitudinal research. An empirical basis for the primary prevention of psychosocial disorders. Oxford: Oxford University Press, 1981:61-5.

19 Altman DG. Practical statistics for medical research. London: Chapman and Hall, 1991.

20 Baltagi BH, Chang Y. Incomplete panels: a comparative study of alternative estimators for the unbalanced one-way error component regression model.J Econom 1994;62:6789 .

21 Royston P, Altman DG. Regression using fractional polynomials of continuous covariates: parsimonious parametric modelling (with discussion). Applied Stat 1994;43:42967.

22 Hack M, Weissman B, Breslau N, Klein N, Borawski Clark E, Fanaroff AA. Health of very low birth weight children during their first eight years. J Pediatr 1993;122:887-92.

23 Shenkin SD, Starr JM, Deary IJ. Birth weight and cognitive ability in childhood: a sysShenkin SD, Starr JM, Deary IJ. Birth weight an
tematic review. Psychol Bull 2004;130:989-1013.

24 Boomsma DI, Vink JM, van Beijsterveldt TC, de Geus EJ, Beem AL, Mulder EJ, et al. Netherlands twin register: a focus on longitudinal research. Twin Res 2002;5:401-6.

25 Breslau N. Psychiatric sequelae of low birth weight. Epidemiol Rev 1995;17:96-106.

26 Matte TD, Bresnahan M, Begg MD, Susser E. Influence of variation in birth weight within normal range and within sibships on IQ at age 7 years: cohort study. $B M J$ 2001;323:310-4.

27 Boomsma DI, van Beijsterveldt CE, Rietveld MJ, Bartels M, van Baal GC. Genetics mediate relation of birth weight to childhood IQ. BMJ 2001;323:1426-7.

(Accepted 16 September 2005)

doi 10.1136/bmj.38633.594387.3A

Department of Epidemiology and Population Health, London School of Hygiene and Tropical Medicine, London WC1E 7HT

Georgina A Ronalds research assistant

Bianca L De Stavola reader in biostatistics

David A Leon professor of epidemiology

Correspondence to: D A Leon david.leon@lshtm.ac.uk 